\title{
Analysis and Design of Derivative Free Filters against Derivative Based Filter on the Simulated Model of a Three Phase Induction Motor
}

\author{
Ravikumar Jagadeesan ${ }^{1 *}$, Subramanian Srikrishna ${ }^{1}$, Prakash Jagadeesan ${ }^{2}$ \\ ${ }^{1}$ Department of Electrical Engineering, Annamalai University, Annamalainagar, India \\ ${ }^{2}$ Department of Instrumentation Engineering, Madras Institute of Technology, \\ Anna University, Chennai, India \\ E-mail:sriram1505@gmail.com \\ Received December 4, 2009; revised January 16, 2010; accepted February 20, 2010
}

\begin{abstract}
Recursive state estimation methods have aroused substantial attraction among many researchers and in particular, the drives research fraternity has shown increased interest in recent years. State estimators that surrogate direct measurements play an integral part in the operation of modern a.c. drives. Their robustness and accuracy are very much decisive for the performance of the drive. In this paper, a comparative analysis of the three nonlinear filtering schemes to estimate the states of a three phase induction motor on the simulated model is presented. The efficacy of Ensemble Kalman Filter (EnKF) against the traditional Jacobian based Filter or Extended Kalman Filter (EKF) and almost forbidden, hitherto least-attempted Unscented Kalman Filter (UKF) is very much exemplified. Theoretical aspects and comparative simulation results are investigated comprehensively with respect to three different scenarios viz., step changes in load torque, speed reversal, and low speed operation. Also, "Monte Carlo Simulation" runs have been exploited very extensively to show the superior practical usefulness of EnKF, by which the minimum mean square error (MMSE), which is often used as the performance index, ostensibly gets mitigated very radically by the proposed approach. The results throw light on alleviating the intrinsic intricacies encountered in EKF in parlance with the observer theory.
\end{abstract}

Keywords: Ensemble Kalman Filter [EnKF], Extended Kalman Filter [EKF], Three Phase Induction Motor [IM], State Estimation,Unscented Kalman Filter [UKF]

\section{Introduction}

Nonlinear system design using observers is incredibly a very rich area and has been well-researched over the past five decades by the researchers of induction motor control. In general an estimator is defined as a dynamic system, whose state variables are estimates of some other system (e.g., electrical machine) [1].

A plethora of nonlinear state estimation tools are available in the literature and among those a number of workers in the observer design for state and parameter estimation of IM attempted by augmenting the state with unknown parameters, were extensively based on the conceptually simple and celebrated Extended Kalman Filter (EKF), which is very well-known as a recursive nonlinear state estimator, derived by the direct lineariza- tion of state transition function and measurement equation for extending the (linear) Kalman filter in to the nonlinear filtering area [2-13].

Whilst, the well-established EKF which has been distinguished to be the best for processing noisy discrete measurements and for attaining high accuracy state estimates of nonlinear dynamic system in most of the situations, it suffers from the following serious shortcomings [14].

- Costly calculation of Jacobian matrices which are trivial in most applications and often results in implementation difficulties.

- It requires linearization of state transition and measurement functions at each and every sampling instant and first order linearization introduces huge errors in mean and covariance of the state vector, thus leading 
to biasedness of its estimate.

- Lack of unwieldy analytical methods for appropriate selection of model covariances.

More recently, derivative free nonlinear state estimation tools such as Unscented Kalman filter [UKF] with deterministic sampling and Ensemble Kalman Filter [EnKF] which utilizes stochastic sampling approach, have been proposed to address the well-recognized demerits of the most popular EKF. These relatively new nonlinear filtering strategies do not involve any linearization that is required by the well-known EKF, thus yielding enhanced state estimates and have been shown to be a viable alternative to EKF in a wide diversity of applications.

Unscented Kalman Filter [UKF] introduced by Julier and Uhlmann [15], can capture the posterior mean and covariance precisely to third-order for any nonlinearity. UKF, inarguably a novel state estimator, has received very little attention among the researchers in the drives research group. Owing to its numerous advantages possessed by UKF, which were even though exploited very well in the field of chemical engineering, the major flaws posed by the model-dependency deprived of it from the applications in state and parameter estimation as applied to induction motor drives. Results exhibit that the UKF consistently outperforms the EKF in terms of state prediction and estimation errors [16].

The studies make use of UKF for state observation, in which simulation results obviously depict that several inherent properties of UKF recommending its use over EKF in nonlinear filtering problems [17]. Ironically, the characteristics of a new evolutional algorithm Square Root Unscented Kalman Filter [SRUKF], proposed by Rudolph Van Der Merwe and Eric. A. Wan [18], have been very well explored against the EKF by Jie Li et al. [19], and the comparitive results indicate that SRUKF does not display its properties and rather it increases the complexity of the method and so the computational cost. This has led to a conclusion that EKF is still the more realistic state estimation algorithm of induction motor drives.

A radical step in the filtering of nonlinear systems was the development of the Ensemble Kalman Filter [EnKF]. EnKF, a derivative free filter, proposed by Evenson, and which employs a stochastic sampling approach, can be used for handling the state estimation problems connected with systems involving discontinuities. Sample points straddle the discontinuity by which they are approximated. EnKF approximates multi-dimensional integration involved in propagation and update steps using Monte-Carlo sampling. Computation steps are very similar to UKF. It is a new class of particle filter and reasonable estimates can be obtained even by the use of 50 to 100 ensemble sizes. The merits of EnKF are listed as below [20].
- The model need not be smooth and differentiable.

- The state noise can be placed anywhere, for example on uncertain parameters and the noise distribution pattern can either be non-additive or non-Gaussian.

Since linearization is not involved in the calculation of state prediction and covariance in EnKF, the Kalman gain estimates are very much exact. This accurate gain at the end leads to improved estimates. Evenson [20], provides a thorough assessment of the theoretical formulation and practical implementation of the EnKF. Also an excellent review of the theoretical properties and applications of EnKF were also asserted by Gerrit Burgers et al. [21].

Drawing inspiration from the encouraging results of EnKF in the fields of chemical engineering [22], weather forecasting etc., [20,21], the behaviour of the EnKF algorithm is explored on the simulated model of a three phase induction motor, which is the main contribution of this paper. It is to be understood that no detailed investigations on EnKF to estimate the states of a three phase induction motor were realized. The EnKF algorithm is designed, analyzed, implemented and its effectiveness is evaluated with EKF and UKF under three different circumstances viz., step changes in load torque, speed reversal and low speed operation. Computer simulations have been carried out in the presence of additive state and measurement uncertainties to substantiate the test results of EnKF.

The organisation of the paper is as follows: After the introduction in Section 1, Section 2 discusses in detail the formulation of EnKF algorithm for state estimation of a three phase IM. Simulation studies are reported in Section 3 and the main concluding remarks drawn from the analysis of the simulation results are discussed in Section 4. EKF and UKF algorithms are provided in Appendices A and B respectively.

\section{State Estimation}

Consider a nonlinear system represented by the following nonlinear differential equations:

$$
\begin{gathered}
\frac{d x}{d t}=F[x(t), u(t)] \\
y=G[x(t), u(t)]
\end{gathered}
$$

Equation (1) is a state equation and Equation (2) describes the relation between state and measurement variables. In order to describe a discrete nonlinear system, Equations (1) and (2) can be functionally represented in discrete forms as:

$$
\begin{aligned}
& x(k)=f[x(k-1), u(k-1)]+w(k) \\
& y(k)=g[x(k-1), u(k-1)]+v(k)
\end{aligned}
$$


where $\mathrm{x}(\mathrm{k}) \in \mathrm{R}^{\mathrm{n}}$ is the system state vector, $\mathrm{u}(\mathrm{k}) \in \mathrm{R}^{\mathrm{m}}$ is the known system input, $\mathrm{w}(\mathrm{k}) \in \mathrm{R}^{\mathrm{p}}$ is the state noise, $\mathrm{y}(\mathrm{k}) \in \mathrm{R}^{\mathrm{r}}$ is the measured variable and $\mathrm{v}(\mathrm{k}) \in \mathrm{R}^{\mathrm{r}}$ is the measurement noise . The parameter $\mathrm{k}$ represents the sampling instant and the symbol $\mathrm{f}$ is a (possibly nonlinear) state transition function and $g$ is a (possibly nonlinear) measurement function.

The objective of the recursive Bayesian state estimation problem is to find the mean and variance of a random variable $\mathrm{x}(\mathrm{k})$ using the conditional probability density function $\mathrm{p}\left[\mathbf{x}(\mathrm{k}) \mid \mathbf{Y}^{(\mathrm{k})}\right] . \quad \mathbf{Y}^{(\mathrm{k})}$ denotes the set of all the available measurements, i.e. $\mathrm{Y}^{\mathrm{k}} \triangleq\{\mathrm{y}(\mathrm{k}), \mathrm{y}(\mathrm{k}$ $-1), \ldots . .$.$\} As reported by Arulampalam et al. [23], the$ posterior density $\mathrm{p}\left[\mathbf{x}(\mathrm{k}) \mid \mathbf{Y}^{\mathrm{k}}\right]$ is estimated in two steps: (a) prediction step, which is computed before obtaining an observation, and, (b) update step, which is computed after obtaining an observation. In the prediction step, the posterior density $\mathrm{p}\left[\mathbf{x}(\mathrm{k}-1) \mid \mathbf{Y}^{\mathrm{k}-1}\right]$ at the previous time step is propagated into the next time step through the transition density $\{\mathrm{p}[\mathbf{x}(\mathrm{k}) \mid \mathbf{x}(\mathrm{k}-1)]\}$ as follows:

$$
\mathrm{p}\left[\mathbf{x}(\mathrm{k}) \mid \mathbf{Y}^{\mathrm{k}-1}\right]=\int \mathrm{p}[\mathbf{x}(\mathrm{k}) \mid \mathbf{x}(\mathrm{k}-1)] \mathrm{p}\left[\mathbf{x}(\mathrm{k}-1) \mid \mathbf{Y}^{\mathrm{k}-1}\right] \mathrm{d} \mathbf{x}(\mathrm{k}-1)
$$

The update stage involves the application of Bayes' rule:

$$
\mathrm{p}\left[\mathbf{x}(\mathrm{k}) \mid \mathbf{Y}^{\mathrm{k}}\right]=\frac{\mathrm{p}[\mathbf{y}(\mathrm{k}) \mid \mathbf{x}(\mathrm{k})]}{\mathrm{p}\left[\mathbf{y}(\mathrm{k}) \mid \mathbf{Y}^{\mathrm{k}-1}\right]} \times \mathrm{p}\left[\mathbf{x}(\mathrm{k}) \mid \mathbf{Y}^{\mathrm{k}-1}\right]
$$

$$
\mathrm{p}\left[\mathrm{y}(\mathrm{k}) \mid \mathbf{Y}^{\mathrm{k}-1}\right]=\int \mathrm{p}[\mathrm{y}(\mathrm{k}) \mid \mathrm{x}(\mathrm{k})] \mathrm{p}\left[\mathbf{x}(\mathrm{k}) \mid \mathbf{Y}^{\mathrm{k}-1}\right] \mathrm{d} \mathbf{x}(\mathrm{k})
$$

where,
Combining (5), (6) and (7)

$$
\mathrm{p}\left[\mathbf{x}(\mathrm{k}) \mid \mathbf{Y}^{\mathrm{k}}\right]=\frac{\mathrm{p}[\mathbf{y}(\mathrm{k}) \mid \mathbf{x}(\mathrm{k})]\left[\int \mathrm{p}[\mathbf{x}(\mathrm{k}) \mid \mathbf{x}(\mathrm{k}-1)] \mathrm{p}\left[\mathbf{x}(\mathrm{k}-1) \mid \mathbf{Y}^{\mathrm{k}-1}\right] \mathrm{d} \mathbf{x}(\mathrm{k}-1)\right]}{\int \mathrm{p}[\mathrm{y}(\mathrm{k}) \mid \mathrm{x}(\mathrm{k})] \mathrm{p}\left[\mathbf{x}(\mathrm{k}) \mid \mathbf{Y}^{\mathrm{k}-1}\right] \mathrm{d} \mathbf{x}(\mathrm{k})}
$$

Equation (8) describes how the conditional posterior density function propagates from $\mathrm{p}\left[\mathbf{x}(\mathrm{k}-1) \mid \mathbf{Y}^{\mathrm{k}-1}\right]$ to $\mathrm{p}\left[\mathbf{x}(\mathrm{k}) \mid \mathbf{Y}^{\mathrm{k}}\right]$. The properties of the state transition Equation (3) are accounted through the transition density function $\mathrm{p}[\mathbf{x}(\mathrm{k}) \mid \mathbf{x}(\mathrm{k}-1)]$ while $\mathrm{p}[\mathbf{y}(\mathrm{k}) \mid \mathbf{x}(\mathrm{k})]$ reflects the nonlinear measurement function. The prediction and update strategy provide an optimal solution to the state estimation, which, unfortunately, involves high-dimensional integration. The exact analytical solution to the recursive propagation of the posterior density is very difficult to obtain. But, solutions do exist in certain cases [25]. While dealing with nonlinear systems, it becomes necessary to develop approximate and computationally tractable sub-optimal solutions to the above sequential Bayesian estimation problem.

$$
\hat{\mathbf{x}}^{(\mathrm{i})}(\mathrm{k} \mid \mathrm{k}-1)=\hat{\mathbf{x}}^{(\mathrm{i})}(\mathrm{k}-1 \mid \mathrm{k}-1)+\left[\int_{(\mathrm{k}-1) \mathrm{T}}^{\mathrm{kT}} \mathrm{F}[\mathbf{x}(\tau), \mathbf{u}(\mathrm{k}-1)] \mathrm{d} \tau\right]+\mathbf{w}^{(\mathrm{i})}(\mathrm{k}): \mathrm{i}=1,2, \ldots . \mathrm{N}
$$

These particles are then used to estimate the sample mean and covariance as follows:

$$
\begin{gathered}
\overline{\mathbf{x}}(\mathrm{k} \mid \mathrm{k}-1)=\frac{1}{\mathrm{~N}} \sum_{\mathrm{i}=1}^{\mathrm{N}} \hat{\mathbf{x}}^{(\mathrm{i})}(\mathrm{k} \mid \mathrm{k}-1) \\
\overline{\mathbf{y}}(\mathrm{k} \mid \mathrm{k}-1)=\frac{1}{\mathrm{~N}} \sum_{\mathrm{i}=1}^{\mathrm{N}} \mathrm{H}\left[\hat{\mathbf{x}}^{(\mathrm{i})}(\mathrm{k} \mid \mathrm{k}-1)\right]+\mathbf{v}^{(\mathrm{i})}(\mathrm{k})
\end{gathered}
$$

\subsection{Unconstrained State Estimation Using Ensemble Kalman Filter}

In this section we describe the most general form of the EnKF as available in the literature (Gillijns et al. [24], Prakash et al. [25]). The EnKF is initialized by drawing $\mathrm{N}$ particles $\left\{\mathbf{x}^{(\mathrm{i})}(0 \mid 0)\right\}$ from a given distribution. At each time step, $\mathrm{N}$ samples $\left\{\mathbf{w}^{(\mathrm{i})}(\mathrm{k}-1), \mathbf{v}^{(\mathrm{i})}(\mathrm{k}): \mathrm{i}=1, . . \mathrm{N}\right\}$ for $\{\mathbf{w}(\mathrm{k})\}$ and $\{\mathbf{v}(\mathrm{k})\}$ are drawn randomly using the distributions of state noise and measurement noise. These sample points together with particles $\left\{\hat{\mathbf{x}}^{(\mathrm{i})}(\mathrm{k}-1\right.$ $\mid \mathrm{k}-1): \mathrm{i}=1, . . \mathrm{N}\}$ are then propagated through the system dynamics to compute a cloud of transformed sample points (particles) as follows:$$
\begin{aligned}
& \mathrm{P}_{\varepsilon, \mathbf{e}}(\mathrm{k})=\frac{1}{\mathrm{~N}-1} \sum_{\mathrm{i}=1}^{\mathrm{N}}\left[\boldsymbol{\varepsilon}^{(\mathrm{i})}(\mathrm{k})\right]\left[\mathrm{e}^{(\mathrm{i})}(\mathrm{k})\right]^{\mathrm{T}} \\
& \mathrm{P}_{\mathbf{e}, \mathbf{e}}(\mathrm{k})=\frac{1}{\mathrm{~N}-1} \sum_{\mathrm{i}=1}^{\mathrm{N}}\left[\mathbf{e}^{(\mathrm{i})}(\mathrm{k})\right]\left[\mathbf{e}^{(\mathrm{i})}(\mathrm{k})\right]^{\mathrm{T}}
\end{aligned}
$$

where, 


$$
\begin{gathered}
\boldsymbol{\varepsilon}^{(\mathrm{i})}(\mathrm{k})=\hat{\mathbf{x}}^{(\mathrm{i})}(\mathrm{k} \mid \mathrm{k}-1)-\overline{\mathbf{x}}(\mathrm{k} \mid \mathrm{k}-1) \\
\mathbf{e}^{(\mathrm{i})}(\mathrm{k})=\mathrm{H}\left[\hat{\mathbf{x}}^{(\mathrm{i})}(\mathrm{k} \mid \mathrm{k}-1)\right]+\mathbf{v}^{(\mathrm{i})}(\mathrm{k})-\overline{\mathbf{y}}(\mathrm{k} \mid \mathrm{k}-1)
\end{gathered}
$$

The Kalman gain and samples of updated particles are then computed as follows:

$$
\begin{gathered}
\mathrm{K}(\mathrm{k})=\mathrm{P}_{\varepsilon, \mathrm{e}}(\mathrm{k})\left[\mathrm{P}_{\mathrm{e}, \mathrm{e}}(\mathrm{k})\right]^{-1} \\
\Upsilon^{(\mathrm{i})}(\mathrm{k} \mid \mathrm{k}-1)=\left\{\mathrm{y}(\mathrm{k})-\mathrm{H}\left[\hat{\mathbf{x}}^{(\mathrm{i})}(\mathrm{k} \mid \mathrm{k}-1)\right]+\mathbf{v}^{(\mathrm{i})}(\mathrm{k})\right\} \\
\hat{\mathbf{x}}^{(\mathrm{i})}(\mathrm{k} \mid \mathrm{k})=\hat{\mathbf{x}}^{(\mathrm{i})}(\mathrm{k} \mid \mathrm{k}-1)+\mathrm{K}(\mathrm{k}) \Upsilon^{(\mathrm{i})}(\mathrm{k} \mid \mathrm{k}-1) \\
\Upsilon^{(\mathrm{i})}(\mathrm{k} \mid \mathrm{k})=\left\{\mathbf{y}(\mathrm{k})-\mathrm{H}\left[\hat{\mathbf{x}}^{(\mathrm{i})}(\mathrm{k} \mid \mathrm{k})\right]+\mathbf{v}^{(\mathrm{i})}(\mathrm{k})\right\}
\end{gathered}
$$

where $i=1,2, \ldots N$. The updated state estimate is computed as the mean of the updated cloud of particles, i.e.

$$
\hat{\mathbf{x}}(\mathrm{k} \mid \mathrm{k})=\frac{1}{\mathrm{~N}} \sum_{\mathrm{i}=1}^{\mathrm{N}} \hat{\mathbf{x}}^{(\mathrm{i})}(\mathrm{k} \mid \mathrm{k})
$$

The covariance of the updated estimates can be computed as

$$
\begin{gathered}
\mathbf{P}(\mathrm{k} \mid \mathrm{k})=\frac{1}{\mathrm{~N}-1} \sum_{\mathrm{i}=1}^{\mathrm{N}}\left[\boldsymbol{\gamma}^{(\mathrm{i})}(\mathrm{k})\right]\left[\boldsymbol{\gamma}^{(\mathrm{i})}(\mathrm{k})\right]^{\mathrm{T}} \\
\boldsymbol{\gamma}^{(\mathrm{i})}(\mathrm{k})=\hat{\mathbf{x}}^{(\mathrm{i})}(\mathrm{k} \mid \mathrm{k})-\hat{\mathbf{x}}(\mathrm{k} \mid \mathrm{k})
\end{gathered}
$$

While $\mathbf{P}(\mathrm{k} \mid \mathrm{k})$ is not required in subsequent computations of the EnKF, it can serve as a measure of the uncertainty associated with the updated estimates. It may be noted that in Equation (15), the predicted observations have been perturbed by drawing samples from the measurement noise distribution. The random perturbations have to be carried out so that the updated sample covariance matrix of the ensemble Kalman filter matches with that of the updated error covariance matrix of the Kalman filter [20]. This step helps in creating a new ensemble of states having correct error statistics for the update step [24]. It may be noted that the accuracy of the estimates depends on the number of data points $(\mathrm{N})$. Prakash et al. [25] have indicated that the ensemble size between 50 and 100 suffices even for large dimensional systems.

\section{Induction Motor Model}

In order to apply nonlinear filters for the state estimation of a three phase IM, the first step in the estimation process is the precise definition of a mathematical model, which appropriately represents the real behaviour of a motor. The most preferred way of capturing the dynamics of an induction motor is by a fifth-order differential equation with two inputs $\left(\mathrm{v}_{\mathrm{s} \alpha}, \mathrm{v}_{\mathrm{s} \beta}\right)$ and five state variables $\left(\mathrm{i}_{\mathrm{s} \alpha}, \mathrm{i}_{\mathrm{s} \beta}, \Psi_{\mathrm{r} \alpha}, \Psi_{\mathrm{r} \beta}, \mathrm{w}_{\mathrm{m}}\right)$ are available for measurement. One of the model structures used by Murat Burat et al. [2], its associated parameters (see Table 1) and noise covariance matrices have been used to generate the true value of the state variables.

The IM is modelled by the following differential equations in the frame of references connected to the stator [2]:

$$
\begin{aligned}
& \frac{\mathrm{di}_{\mathrm{s} \alpha}}{\mathrm{dt}}=\dot{\mathrm{X}}_{1}=-\left[\frac{\mathrm{R}_{\mathrm{s}}}{\mathrm{L}_{\sigma}}+\frac{\mathrm{R}_{\mathrm{r}}^{\prime} \mathrm{L}_{\mathrm{m}}^{2}}{\mathrm{~L}_{\mathrm{r}}^{\prime 2} \mathrm{~L}_{\sigma}}\right] i_{\mathrm{s} \alpha}+\frac{\mathrm{R}_{\mathrm{r}}^{\prime} \mathrm{L}_{\mathrm{m}}}{\mathrm{L}_{\mathrm{r}}^{\prime 2} \mathrm{~L}_{\sigma}} \psi_{\mathrm{r} \alpha}+\frac{\mathrm{L}_{\mathrm{m}}}{\mathrm{L}_{\sigma} \mathrm{L}_{\mathrm{r}}^{\prime}} \mathrm{P}_{\mathrm{p}} \omega_{\mathrm{m}} \psi_{\mathrm{r} \beta}+\frac{1}{\mathrm{~L}_{\sigma}} \mathrm{V}_{\mathrm{s} \alpha} \\
& \frac{\mathrm{di} \mathrm{s}_{\mathrm{s}}}{\mathrm{dt}}=\dot{\mathrm{X}}_{2}=-\left[\frac{\mathrm{R}_{\mathrm{s}}}{\mathrm{L}_{\sigma}}+\frac{\mathrm{R}_{\mathrm{r}}^{\prime} \mathrm{L}_{\mathrm{m}}^{2}}{\mathrm{~L}_{\mathrm{r}}^{\prime 2} \mathrm{~L}_{\sigma}}\right] \mathrm{i}_{\mathrm{s} \beta}+\frac{\mathrm{R}_{\mathrm{r}}^{\prime} \mathrm{L}_{\mathrm{m}}}{\mathrm{L}_{\mathrm{r}}^{\prime 2} \mathrm{~L}_{\sigma}} \psi_{\mathrm{r} \beta}-\frac{\mathrm{L}_{\mathrm{m}}}{\mathrm{L}_{\sigma} \mathrm{L}_{\mathrm{r}}^{\prime}} \mathrm{P}_{\mathrm{p}} \omega_{\mathrm{m}} \psi_{\mathrm{r} \alpha}+\frac{1}{\mathrm{~L}_{\sigma}} \mathrm{V}_{\mathrm{s} \beta}
\end{aligned}
$$

$$
\begin{gathered}
\frac{\mathrm{d} \psi_{\mathrm{r} \alpha}}{\mathrm{dt}}=\dot{\mathrm{X}}_{3}=\frac{\mathrm{R}_{\mathrm{r}}^{\prime}}{\mathrm{L}_{\mathrm{r}}^{\prime}} \mathrm{L}_{\mathrm{m}} \mathrm{i}_{\mathrm{s} \alpha}-\frac{\mathrm{R}_{\mathrm{r}}^{\prime}}{\mathrm{L}_{\mathrm{r}}^{\prime}} \psi_{\mathrm{r} \alpha}-\mathrm{P}_{\mathrm{p}} \omega_{\mathrm{m}} \psi_{\mathrm{r} \beta} \\
\frac{\mathrm{d} \psi_{\mathrm{r} \beta}}{\mathrm{dt}}=\dot{\mathrm{X}}_{4}=\frac{\mathrm{R}_{\mathrm{r}}^{\prime}}{\mathrm{L}_{\mathrm{r}}^{\prime}} \mathrm{L}_{\mathrm{m}} \mathrm{i}_{\mathrm{s} \beta}-\frac{\mathrm{R}_{\mathrm{r}}^{\prime}}{\mathrm{L}_{\mathrm{r}}^{\prime}} \psi_{\mathrm{r} \beta}+\mathrm{P}_{\mathrm{p}} \omega_{\mathrm{m}} \psi_{\mathrm{r} \alpha} \\
\frac{\mathrm{d} \omega_{\mathrm{m}}}{\mathrm{dt}}=\dot{\mathrm{X}}_{5}=-\frac{3}{2} \frac{\mathrm{P}_{\mathrm{p}}}{\mathrm{J}_{\mathrm{L}}} \frac{\mathrm{L}_{\mathrm{m}}}{\mathrm{L}_{\mathrm{r}}^{\prime}} \psi_{\mathrm{r} \beta} \mathrm{i}_{\mathrm{s} \alpha}+\frac{3}{2} \frac{\mathrm{P}_{\mathrm{p}}}{\mathrm{J}_{\mathrm{L}}} \frac{\mathrm{L}_{\mathrm{m}}}{\mathrm{L}_{\mathrm{r}}^{\prime}} \psi_{\mathrm{r} \alpha} \mathrm{i}_{\mathrm{s} \beta}-\frac{1}{\mathrm{~J}_{\mathrm{L}}} \mathrm{t}_{\mathrm{L}}
\end{gathered}
$$

The measurement equation is given by:

$$
\mathrm{Y}=\left[\begin{array}{ll}
i_{\mathrm{s} \alpha} & \mathrm{i}_{\mathrm{s} \beta}
\end{array}\right]^{\mathrm{T}}
$$

The value of state variables were initialized as below:

$$
\mathrm{X}(0 \mid 0)=[0 ; 0 ; 0 ; 0 ; 0]
$$

The evolution of true state variables is computed by solving the nonlinear differential equations, using the differential equation solver in MATLAB 7.7. The sampling time is chosen to be as 0.01 and the length of all the simulation trials as 2000 , besides, the state and measurement noises are added in an additive fashion.

\subsection{Design of Derivative Based and Derivative Free Filters}

The algorithm reported in Section 2 and in the appendices $\mathrm{A}$ and $\mathrm{B}$ respectively, have been used to estimate the state variables of the IM, which takes into account of load torque as an additional state variable. In order to generate unbiased state estimates, in all the three nonlinear estimators taken for comparative analysis, it has been assumed that in the presence of load torque variation, 
Table 1. Rated values and parameters of the IM used for simulation study.

\begin{tabular}{ccccccccccccc}
\hline $\begin{array}{c}\mathrm{P} \\
(\mathrm{KW})\end{array}$ & $\mathrm{f}(\mathrm{Hz})$ & $\mathrm{J}_{\mathrm{L}}\left(\mathrm{Kg} \cdot \mathrm{m}^{2}\right)$ & $\mathrm{P}_{\mathrm{p}}$ & $\begin{array}{c}\mathrm{V} \\
(\mathrm{V})\end{array}$ & $\begin{array}{c}\mathrm{I} \\
(\mathrm{A})\end{array}$ & $\mathrm{R}_{\mathrm{s}}(\Omega)$ & $\mathrm{R}_{\mathrm{r}}(\Omega)$ & $\mathrm{L}_{\mathrm{s}}(\mathrm{H})$ & $\mathrm{L}_{\mathrm{r}}(\mathrm{H})$ & $\mathrm{L}_{\mathrm{m}}(\mathrm{H})$ & $\begin{array}{c}\mathrm{N}_{\mathrm{m}} \\
(\mathrm{rpm})\end{array}$ & $\begin{array}{c}\mathrm{T}_{\mathrm{L}} \\
(\mathrm{Nm})\end{array}$ \\
\hline 3 & 50 & 0.05 & 2 & 380 & 6.9 & 2.283 & 2.133 & 0.23 & 0.23 & 0.22 & 1430 & 20 \\
\hline
\end{tabular}

the state equation is augmented with the differential equation which is of the form:

$$
\frac{\mathrm{dt}_{\mathrm{L}}}{\mathrm{dt}}=\dot{\mathrm{X}}_{6}=0
$$

Equation (29) implies that the load torque can vary only in a step-like fashion. The afore-said equation, together with the differential Equations (23) to (27), listed in the preceding sub-section have been used for generating one step ahead predicted state estimates. The state and measurement noise covariance matrices (see Table 2) were initialized as specified in [2]. However the variance linked with the augmented state variable is changed, to attain good responses.

It is to be noted from Table 2 that for EKF and EnKF, identical values of state and measurement noises have been realized. In the lime-light of UKF's supremacy over EKF and since the results produced by the UKF with the alike value of noise covariances, are somewhat not acceptable, the variance associated with the augmented state variable, is further fine tuned to get a fair estimate, and despite our several endeavours, the expected better results were not evolved. It is worth noting that manual tuning of the UKF using trial and error method is simple to carry, but the process is time consuming, and acceptable performance can only be acquired with a great effort from an experienced operator.

It has been assumed that the random errors were present in the noise covariance matrices and the estimation is started with the initial value as shown below:

$$
\mathrm{X}(0 \mid 0)=[0 ; 0 ; 0 ; 0 ; 0]
$$

The initial error covariance matrices reported in [2] have been fixed and are as follows:

Table 2. Initial value of measurement and state noise covariance matrices.

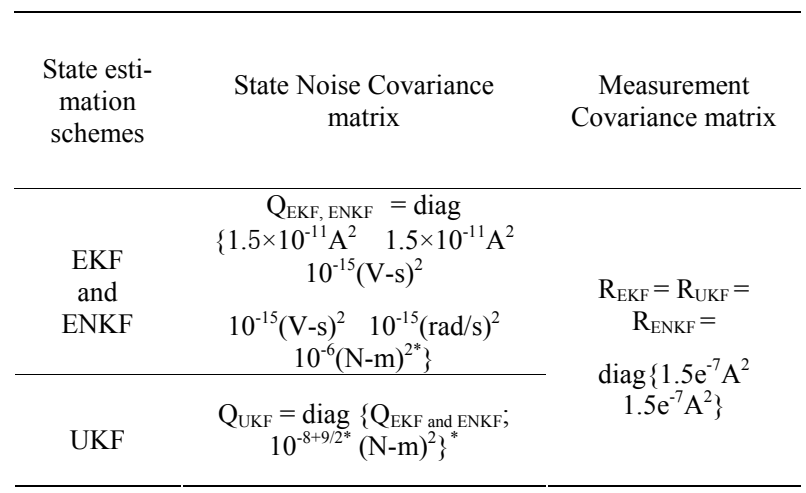

\footnotetext{
* Variance connected with the augmented state variable.
}

$\mathrm{P}=\operatorname{diag}\left\{1 \mathrm{~A}^{2} 1 \mathrm{~A}^{2} 1(\mathrm{~V}-\mathrm{s})^{2} 1(\mathrm{~V}-\mathrm{s})^{2} 1(\mathrm{rad}-\mathrm{s})^{2} 1(\mathrm{~N}-\mathrm{m})^{2}\right\}$

EKF tuning is performed in an ad-hoc style, but the EnKF algorithm differs substantially from the customary approach in the sense that, when the particle size is very small, the EnKF may not always converge or arrive at an optimal solution, and in order to get reasonable responses, the ensemble size must be more, and in our instance, the ensemble size for a single simulation trial, for all the situations tested in our study is chosen as 200. It should be noted that the EnKF algorithm is computationally intensive. The computation time per sampling instant, for a single simulation run with a particle size of 200 , is about 45 minutes on an Intel Core 2 Duo PC.

\section{Simulation Results and Discussion}

\subsection{Test Results}

Computer simulations were performed to test the usefulness of the EnKF algorithm against other state prediction and estimation methods such as EKF and UKF. The simulations were carried out in MATLAB7.7-R2008(b) program on an Intel core 2 Duo Processor with $1.8 \mathrm{GHz}$ CPU and 2 GB RAM. Three different scenarios reported by Murat Burat et al. [2], have been used for the comparative analysis.

\subsubsection{Scenario-I: Step Changes in Load Torque}

The evolution of true and estimated state variables in the presence of step changes in load torque is shown in Figure 1. It is being observed that the estimated values of state variables and the filtered estimate of measured variables track their true value more closely throughout the operating range. The analysis of Figure 1 enables us to conclude that relatively good estimates are obtained from EnKF in comparision with the EKF and UKF. Moreover the estimate of the augmented state variable is determined to be very accurate.

\subsubsection{Scenario-II: Reversal of Speed}

Figure 2 presents the emergence of true and estimated state variables for the speed reversal case and this is accomplished by changing the input frequency from +50 $\mathrm{Hz}$ to $-50 \mathrm{~Hz}$. It is being inferred that the state estimates obtained by EnKF are very accurate, compared to the behaviour of the estimates produced by using the EKF and UKF formulations. It is noteworthy that all the three state estimation schemes taken for comparative study perform exceedingly well in this case. 


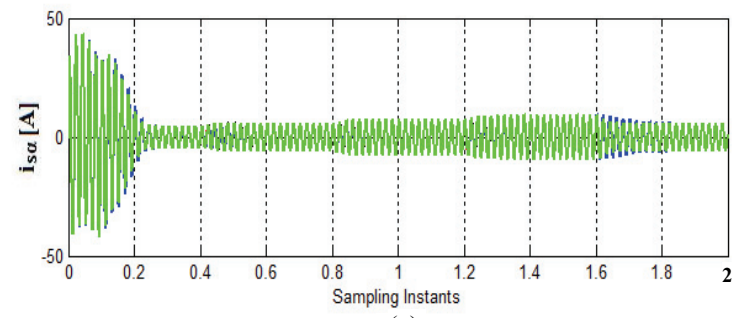

(a)

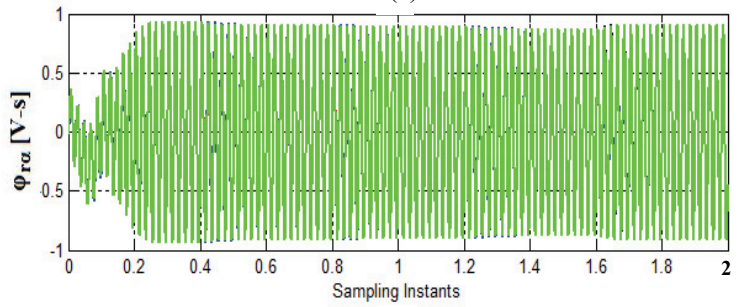

(c)

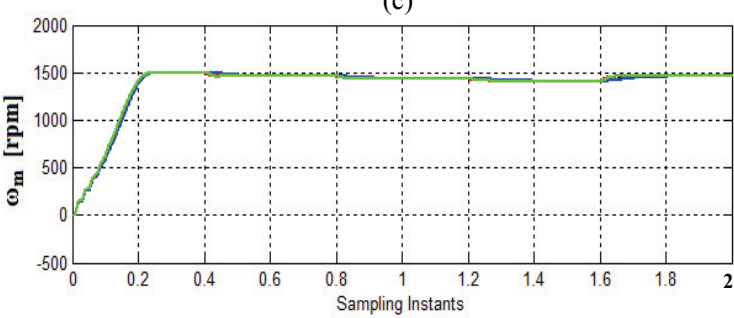

(e)

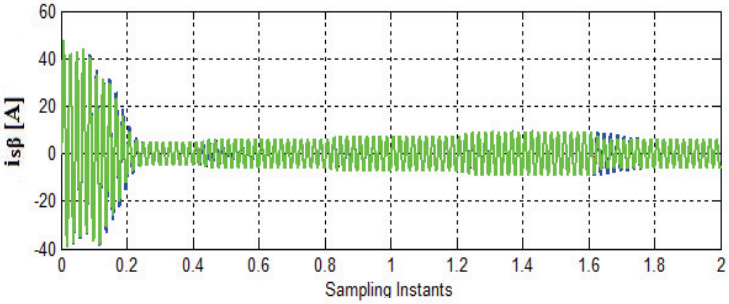

(b)

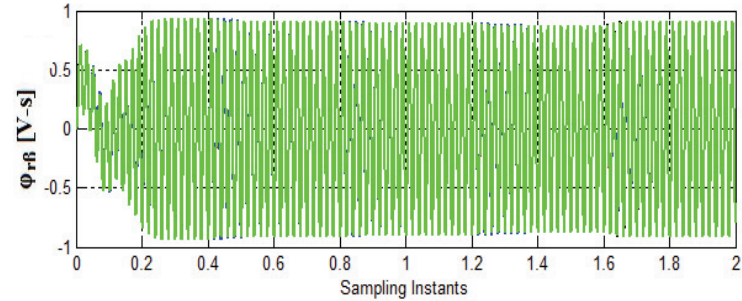

(d)

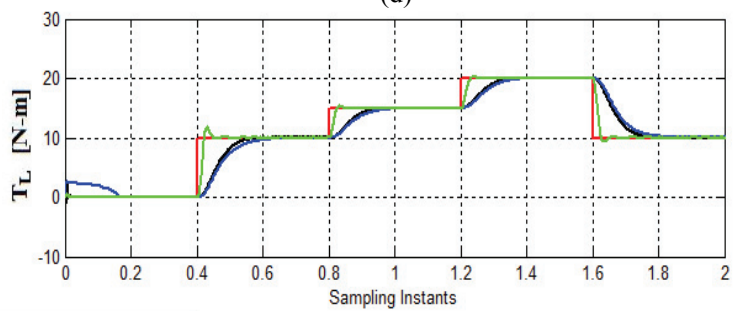

(f)

Figure 1. Evolution of true and estimated state variables for step changes in load torque.

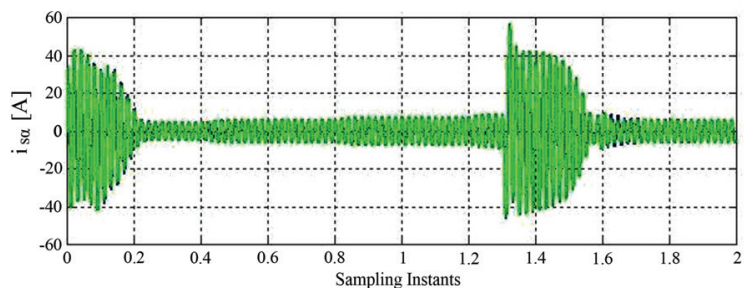

(a)

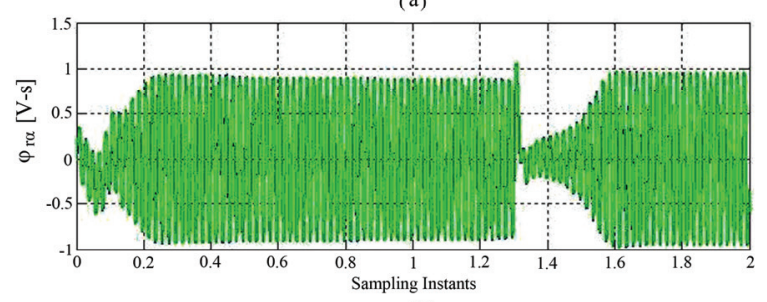

(c)

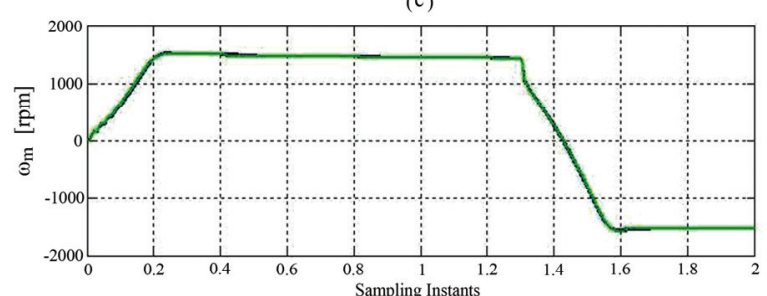

(e)

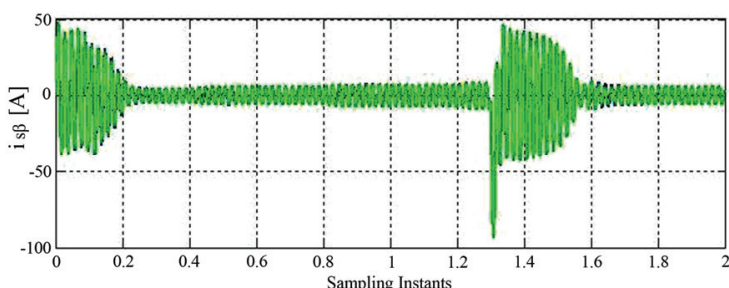

(b)
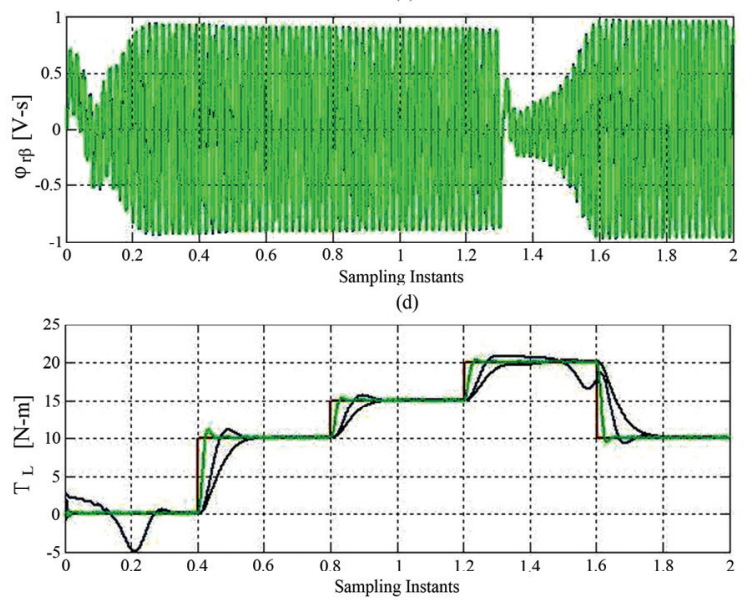

(f)

Figure 2. Emergence of true and estimated state variables for speed reversal. 


\subsubsection{Scenario-III: Low Speed Operation}

One significant aspect being very well examined in the literature is the low speed operation, which was presumed as a serious challenge in the arena of IM drives. This is possible by constantly maintaining $\mathrm{v} / \mathrm{f}$ ratio and the low speed operation results are very well displayed in Figure 3. A closer examination of the Figure 3 discloses that the estimates of speed and rotor fluxes are found to be more precise. It should be noted that the Kalman filter and its variants have demonstrated an acceptable performance in the low speed operation. Regardless of its appreciable results of simulation at low speeds for EKF algorithm, the complexity, computational burden and accuracy issues practically outlaw the choice of EKF algorithm over a low-cost fixed processor.

a) $i_{s a}[A]-S t a t o r$ stationary axis components of stator currents. b) $i_{s \beta}[A]$-Stator stationary axis components of stator currents. c) $\psi_{\mathrm{r \alpha}}[\mathrm{V}$-s] -Rotor stationary axis components of stator flux. d) $\psi_{\mathrm{r} \beta}[\mathrm{V}-\mathrm{s}]$-Rotor stationary axis components of stator flux. e) $\omega_{\mathrm{m}}[\mathrm{rad}-\mathrm{s}]$-Angular velocity. f) $T_{L}[N-m]$-Load torque.

\subsection{Performance Assessment}

The performance of the three nonlinear estimators taken for comparative study must be assessed through simulation, because stochastic systems are involved in these studies. For each case that is being analyzed, a simula-

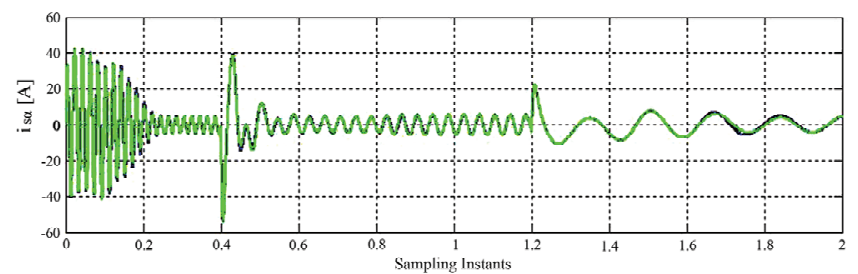

(a)

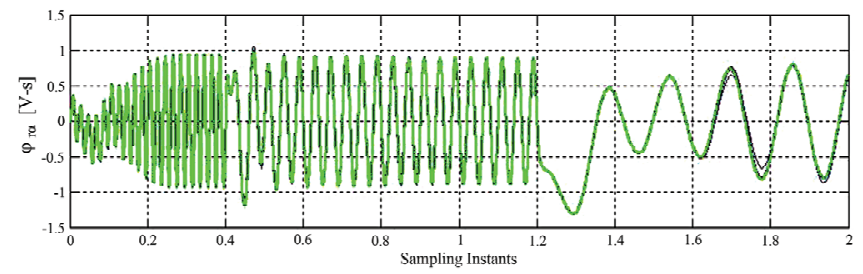

(c)

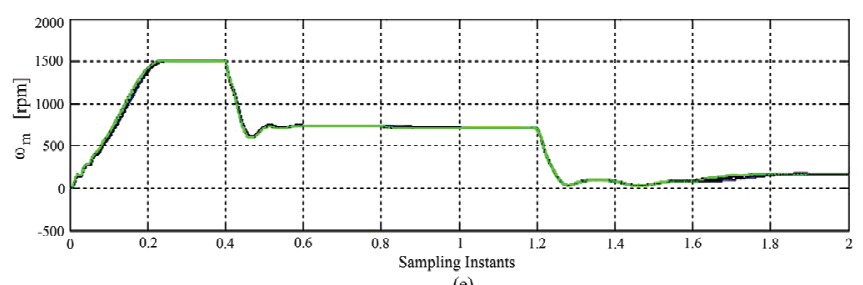

(e) tion run that consists of $\mathrm{N}_{\mathrm{T}}$ (trials) with the length of each simulation trial being equal to $\mathrm{L}$ is conducted. In all the simulation trials, the sum of the squares of the estimation errors, which is truly the difference between the estimated value of the state variables and the true value of the state variables, that have been obtained. The mean of the estimation errors based on 25 Monte Carlo simulations for the EKF, UKF and ENKF are reported in Tables 4,5 and 6 respectively. A close view at the tables makes one to conclude that, the Minimum Mean Square Error [MMSE], which is often used as a performance index is found to be very low for EnKF in all the three different scenarios taken for comparative simulation study. It is apparent from the Table 6 that, MMSE gets lessened by the use of more ensemble sizes. The computational time per sampling instant for an ensemble size of 25 for EnKF is compared with the EKF and UKF and presented in the form of histogram (see Figure 4). Despite the fact that the time-complexity is said to be large, these are well within the capabilities of contemporary signal processing devices, so that a real-time accomplishment is plausible.

\section{Concluding Remarks}

An attempt has been made in this paper to use the EnKF for the estimation of states of a three phase IM. Computer simulations have been performed meticulously to

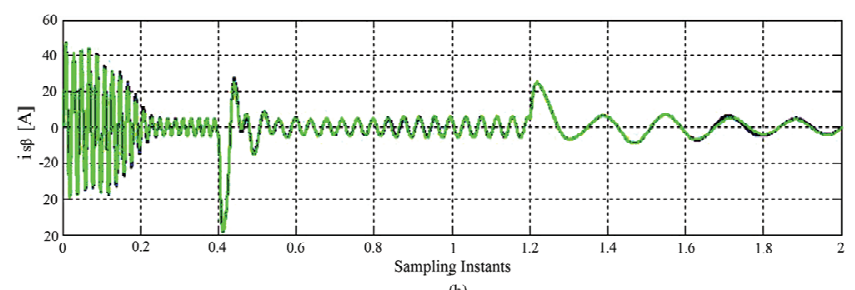

(b)

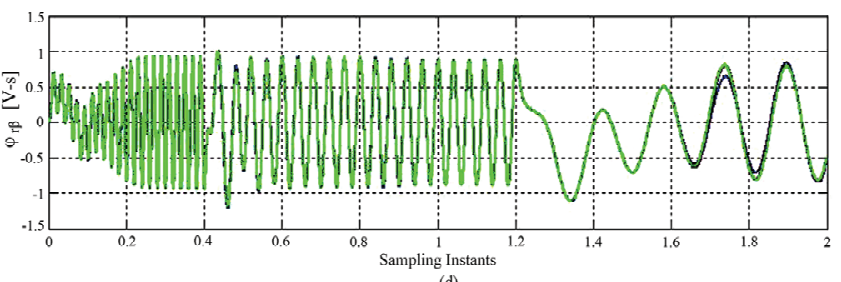

(d)

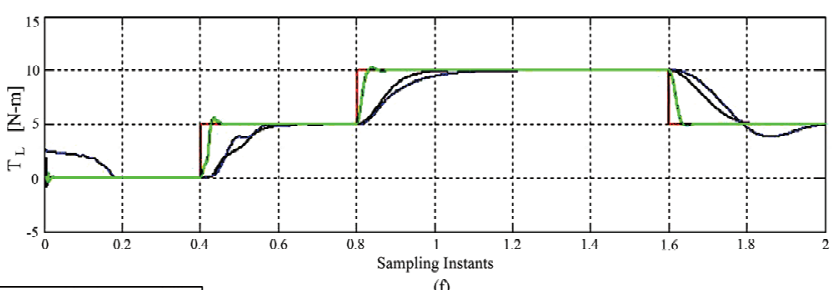

(f)

Figure 3. Emergence of true and estimated state variables for low speed operation. 


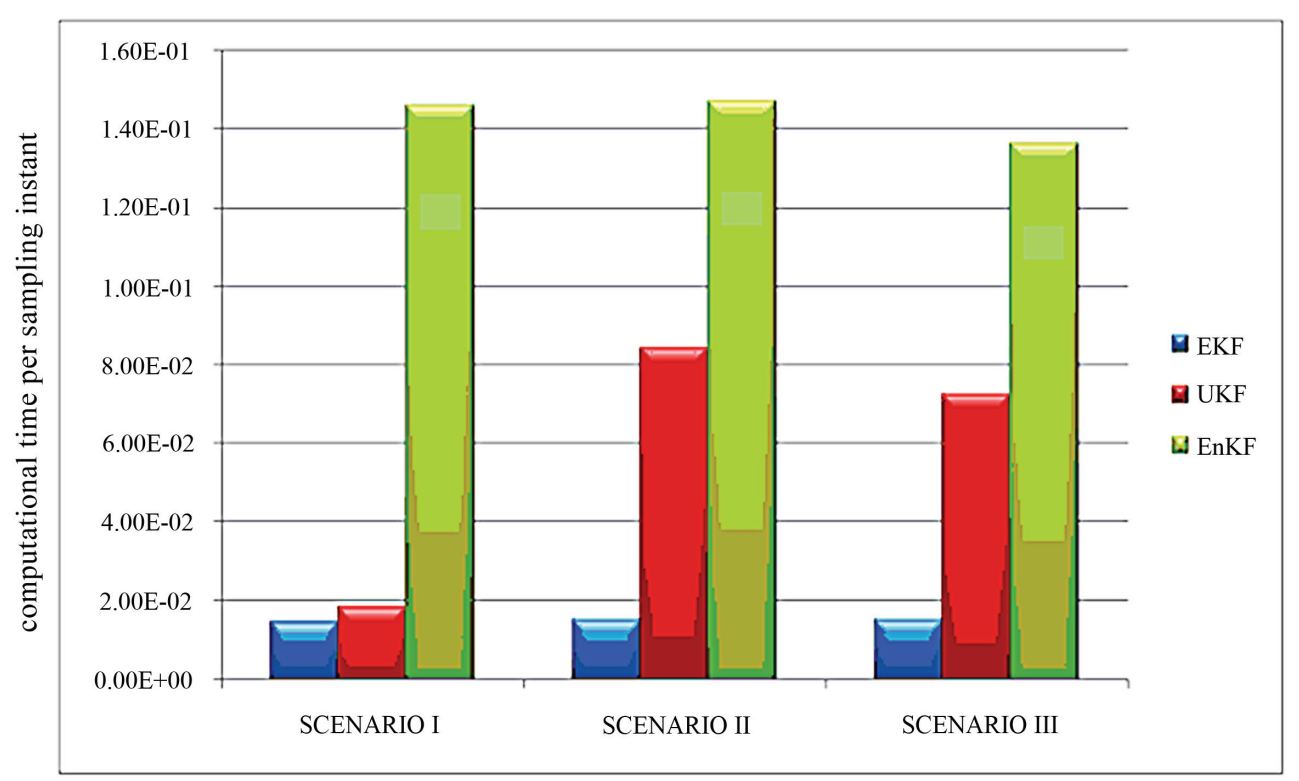

Figure 4. Comparision of execution time of EnKF for a particle size 25 against EKF and UKF.

Table 4. Minimum mean square error (MMSE) values of EKF.

\begin{tabular}{|c|c|c|c|}
\hline STATE & $\begin{array}{c}\text { SCENARIO - } \\
\text { I }\end{array}$ & $\begin{array}{c}\text { SCENARIO - } \\
\text { II }\end{array}$ & $\begin{array}{c}\text { SCENARIO - } \\
\text { III }\end{array}$ \\
\hline ABLES & MEAN & MEAN & MEAN \\
\hline $\mathrm{i}_{\mathrm{s} \alpha}$ & $6.9100 \mathrm{e}^{-2}$ & $6.6720 \mathrm{e}^{-2}$ & $1.8400 \mathrm{e}^{-2}$ \\
\hline $\mathrm{i}_{\mathrm{s} \beta}$ & $6.9093 \mathrm{e}^{-2}$ & $6.6723 \mathrm{e}^{-2}$ & $1.8469 \mathrm{e}^{-2}$ \\
\hline$\psi_{\mathrm{r} \alpha}$ & $6.0288 \mathrm{e}^{-5}$ & $5.8286 \mathrm{e}^{-5}$ & $1.1682 \mathrm{e}^{-4}$ \\
\hline$\psi_{\mathrm{r} \beta}$ & $6.0290 \mathrm{e}^{-5}$ & $5.8282 \mathrm{e}^{-5}$ & $1.3016 \mathrm{e}^{-4}$ \\
\hline$\omega_{\mathrm{m}}$ & $9.4296 \mathrm{e}^{-1}$ & $9.7334 \mathrm{e}^{-1}$ & $4.8508 \mathrm{e}^{-1}$ \\
\hline $\mathrm{t}_{\mathrm{L}}$ & $5.5802 \mathrm{e}^{0}$ & $5.5872 \mathrm{e}^{0}$ & $2.0452 \mathrm{e}^{0}$ \\
\hline
\end{tabular}

Table 5. Minimum mean square error (MMSE) values of UKF.

\begin{tabular}{cccc}
\hline \multirow{2}{*}{$\begin{array}{c}\text { STATE } \\
\text { VARI- } \\
\text { ABLES }\end{array}$} & $\begin{array}{c}\text { SCENARIO }- \\
\text { I }\end{array}$ & $\begin{array}{c}\text { SCENARIO }- \\
\text { MEAN }\end{array}$ & $\begin{array}{c}\text { SCENARIO - } \\
\text { III }\end{array}$ \\
\hline $\mathrm{i}_{\mathrm{s} \alpha}$ & $1.8604 \mathrm{e}^{-1}$ & $2.6480 \mathrm{e}^{-1}$ & $3.1616 \mathrm{e}^{-1}$ \\
$\mathrm{i}_{\mathrm{s} \beta}$ & $1.8611 \mathrm{e}^{-1}$ & $2.6479 \mathrm{e}^{-1}$ & $3.0686 \mathrm{e}^{-1}$ \\
$\psi_{\mathrm{r} \alpha}$ & $1.0164 \mathrm{e}^{-4}$ & $1.4123 \mathrm{e}^{-4}$ & $1.8700 \mathrm{e}^{-3}$ \\
$\Psi_{\mathrm{r} \beta}$ & $1.0357 \mathrm{e}^{-4}$ & $1.4314 \mathrm{e}^{-4}$ & $2.2864 \mathrm{e}^{-3}$ \\
$\omega_{\mathrm{m}}$ & $1.1745 \mathrm{e}^{0}$ & $2.1488 \mathrm{e}^{0}$ & $2.3092 \mathrm{e}^{0}$ \\
$\mathrm{t}_{\mathrm{L}}$ & $4.6709 \mathrm{e}^{0}$ & $4.7167 \mathrm{e}^{0}$ & $2.6369 \mathrm{e}^{0}$ \\
\hline
\end{tabular}

compare the behaviour of EnKF against the EKF and UKF. The main conclusion drawn from this work, is that the inherent flaw of the well-appreciated EKF i.e., the exhaustive Jacobian computation, which is very well the cause of biasedness of its estimate and imposing severe computational cost in real-time implementation were overcome, thanks to the action of EnKF, which provides a derivative free approach for estimation of predicted covariances required in the update step. As evidenced by the results, the EnKF algorithm surpasses EKF and UKF in all the scenarios tested, and a noticeable enhancement in its performance is attained even by the use of 50 to 100 ensemble sizes. This can be claimed as a potential advantage over EKF.

Enlightened by the belief that UKF is a superior alternative of the EKF, though theoretically proven, it is fine tuned to obtain an estimate very nearer to EKF, but even then UKF did not exhibit its properties, and the results achieved are said to be implausible. Additive and Gaussian noise distribution sequence is usually made as an assumption in the state estimation of a three phase IM. However, there are schools of thought supporting the distribution of noise in IM drive system in real-time, as being primarily non-addditive and non-Gaussian in nature. Categorically, the drives research community has been left bewildered by such an apparent dissension and even under such circumstances, the EnKF algorithm will work satisfactorily, which has to be further explored carefully. Conversely, the well-acclaimed EKF can be strictly applied only for restricted class of noise distribution patterns. Because of its conspicuous performance, the EnKF algorithm has an edge over EKF in a wide diversity of applications. The only drawback is the time-complexity, but nevertheless a processor with high 
Table 6. Minimum mean square Error (MMSE) values of EnKF for different ensemble sizes.

\begin{tabular}{|c|c|c|c|c|}
\hline PARTICLE SIZE & STATE VARIABLES & SCENARIO I & SCENARIO II & SCENARIO III \\
\hline \multirow{6}{*}{25} & $\mathrm{i}_{\mathrm{s} \alpha}$ & $7.2293 \mathrm{e}^{-4}$ & $5.5775 \mathrm{e}^{-4}$ & $1.1594 \mathrm{e}^{-4}$ \\
\hline & $i_{s \beta}$ & $7.2395 \mathrm{e}^{-4}$ & $5.5142 \mathrm{e}^{-4}$ & $1.8477 \mathrm{e}^{-4}$ \\
\hline & $\psi_{\text {ru }}$ & $2.3036 \mathrm{e}^{-5}$ & $2.7246 \mathrm{e}^{-5}$ & $2.7319 \mathrm{e}^{-5}$ \\
\hline & $\psi_{\mathrm{r} \beta}$ & $1.9797 \mathrm{e}^{-5}$ & $2.0483 \mathrm{e}^{-5}$ & $2.0248 \mathrm{e}^{-5}$ \\
\hline & $\omega_{\mathrm{m}}$ & $3.2161 \mathrm{e}^{-2}$ & $2.5811 \mathrm{e}^{-2}$ & $1.9117 \mathrm{e}^{-2}$ \\
\hline & $t_{L}$ & $1.4886 \mathrm{e}^{0}$ & $1.3837 \mathrm{e}^{0}$ & $5.0224 \mathrm{e}^{-1}$ \\
\hline \multirow{6}{*}{50} & $\mathrm{i}_{\mathrm{s} a}$ & $5.3629 \mathrm{e}^{-4}$ & $4.3726 \mathrm{e}^{-4}$ & $8.0065 \mathrm{e}^{-5}$ \\
\hline & $i_{s \beta}$ & $5.4094 \mathrm{e}^{-4}$ & $4.3459 \mathrm{e}^{-4}$ & $1.5401 \mathrm{e}^{-4}$ \\
\hline & $\psi_{\mathrm{ru}}$ & $1.3467 \mathrm{e}^{-5}$ & $1.7553 \mathrm{e}^{-5}$ & $1.7393 \mathrm{e}^{-5}$ \\
\hline & $\psi_{\mathrm{r} \beta}$ & $9.0231 \mathrm{e}^{-6}$ & $8.8537 \mathrm{e}^{-6}$ & $8.6287 \mathrm{e}^{-6}$ \\
\hline & $\omega_{\mathrm{m}}$ & $2.8156 \mathrm{e}^{-2}$ & $2.3189 \mathrm{e}^{-2}$ & $1.7070 \mathrm{e}^{-2}$ \\
\hline & $t_{L}$ & $1.4234 \mathrm{e}^{0}$ & $1.3300 \mathrm{e}^{0}$ & $4.8683 \mathrm{e}^{-1}$ \\
\hline \multirow{6}{*}{75} & $i_{s a}$ & $4.5133 \mathrm{e}^{-4}$ & $3.8873 \mathrm{e}^{-4}$ & $7.7783 \mathrm{e}^{-5}$ \\
\hline & $i_{s \beta}$ & $4.5348 \mathrm{e}^{-4}$ & $3.8735 \mathrm{e}^{-4}$ & $1.4255 \mathrm{e}^{-4}$ \\
\hline & $\psi_{\text {ru }}$ & $1.2643 \mathrm{e}^{-5}$ & $1.7070 \mathrm{e}^{-5}$ & $1.7924 \mathrm{e}^{-5}$ \\
\hline & $\psi_{\mathrm{r} \beta}$ & $7.7786 \mathrm{e}^{-6}$ & $7.4994 \mathrm{e}^{-6}$ & $7.2875 \mathrm{e}^{-6}$ \\
\hline & $\omega_{\mathrm{m}}$ & $2.6420 \mathrm{e}^{-2}$ & $2.2476 \mathrm{e}^{-2}$ & $1.5958 \mathrm{e}^{-2}$ \\
\hline & $t_{L}$ & $1.3917 \mathrm{e}^{0}$ & $1.3212 \mathrm{e}^{0}$ & $4.7789 \mathrm{e}^{-1}$ \\
\hline \multirow{6}{*}{100} & $i_{s a}$ & $4.5836 \mathrm{e}^{-4}$ & $3.8299 \mathrm{e}^{-4}$ & $7.0702 \mathrm{e}^{-5}$ \\
\hline & $i_{s \beta}$ & $4.5023 \mathrm{e}^{-4}$ & $3.8734 \mathrm{e}^{-4}$ & $1.3433 \mathrm{e}^{-4}$ \\
\hline & $\psi_{\mathrm{ru}}$ & $9.6340 \mathrm{e}^{-6}$ & $1.3041 \mathrm{e}^{-5}$ & $1.6903 \mathrm{e}^{-5}$ \\
\hline & $\psi_{\mathrm{r} \beta}$ & $6.5697 \mathrm{e}^{-6}$ & $6.3207 \mathrm{e}^{-6}$ & $6.1035 \mathrm{e}^{-6}$ \\
\hline & $\omega_{\mathrm{m}}$ & $2.6116 \mathrm{e}^{-2}$ & $2.1808 \mathrm{e}^{-2}$ & $1.5007 \mathrm{e}^{-2}$ \\
\hline & $\mathrm{t}_{\mathrm{L}}$ & $1.4050 \mathrm{e}^{0}$ & $1.3219 \mathrm{e}^{0}$ & $4.8265 \mathrm{e}^{-1}$ \\
\hline \multirow{6}{*}{150} & $\mathrm{i}_{\mathrm{s} \alpha}$ & $4.2953 \mathrm{e}^{-4}$ & $3.5544 \mathrm{e}^{-4}$ & $6.8404 \mathrm{e}^{-5}$ \\
\hline & $\mathrm{i}_{\mathrm{s} \beta}$ & $4.4175 \mathrm{e}^{-4}$ & $3.6098 \mathrm{e}^{-4}$ & $1.2849 \mathrm{e}^{-4}$ \\
\hline & $\psi_{\mathrm{ra}}$ & $1.1029 \mathrm{e}^{-6}$ & $1.5337 \mathrm{e}^{-5}$ & $1.5158 \mathrm{e}^{-5}$ \\
\hline & $\psi_{r \beta}$ & $2.4206 \mathrm{e}^{-6}$ & $2.0697 \mathrm{e}^{-6}$ & $1.8484 \mathrm{e}^{-6}$ \\
\hline & $\omega_{\mathrm{m}}$ & $2.5491 \mathrm{e}^{-2}$ & $2.2614 \mathrm{e}^{-2}$ & $1.4785 \mathrm{e}^{-2}$ \\
\hline & $\mathrm{t}_{\mathrm{L}}$ & $1.3995 \mathrm{e}^{0}$ & $1.3059 \mathrm{e}^{0}$ & $4.7555 \mathrm{e}^{-1}$ \\
\hline
\end{tabular}

calculation performance can accomplish these require ments. Since the digitized a.c. drives have reached the state-of-the-art of technology, any order of these challenging crossroads can be proven to be mediocre.

\section{References}

[1] P. Vas, "Sensorless Vector and Direct Torque Control," Oxford University Press, New York, 1998. 
[2] M. Burat, S. Bogosyan and M. Gokasan, "Speed Sensorless Estimation for Induction Motors Using Extended Kalman Filters," IEEE Transactions on Industrial Electronics, Vol. 54, No. 1, February 2007, pp. 272-280.

[3] M. Burat, S. Bogosyan and M. Gokasan, "Braided Extended Kalman Filters for Sensorless Estimation in Induction Motors at High-low/Zero Speed," IET Control Theory \& Applications, Vol. 1, No. 4, 2007, pp. 987-998.

[4] M. Burat, S. Bogosyan and M. Gokasan, "Speed Sensorless Direct Torque Control of IMs with Rotor Resistance Estimation," Energy Conversion and Management, Vol. 46, No. 3, 2005, pp. 335-349.

[5] M. Burat, S. Bogosyan and M. Gokasan, "An EKF Based Estimator for Speed Sensorless Vector Control of Induction Motors," Electric Power Components and Systems, Vol. 33, No. 7, 2005, pp. 727-744.

[6] J. Holtz, "Sensorless Control of Induction Machines with or without Signal Injection?" IEEE Transactions on Industrial Electronics, Vol. 53, No. 1, February 2006, pp. 7-30.

[7] J. W. Finch, D. J. Atkinson and P. P. Acarnley, "FullOrder Estimator for Induction Motor States and Parameters," IEE Electric Power Applications, Vol. 145, No. 3, May 1998, pp. 169-179.

[8] C. Lascu, I. Boldea and F. Blaabjerg, "Comparitive Study of Adaptive and Inherently Sensorless Observers for Variable Speed Induction Motor Drives," IEEE Transactions on Industrial Electronics, Vol. 53, No. 1, February 2006, pp. 57-65.

[9] G. G. Soto, E. Mendes and A. Razek, "Reduced-Order Observers for Rotor Flux, Rotor Resistance and Speed Estimation for Vector Controlled Induction Motor Drive Using the Extended Kalman Filter Technique," IEE Proceedings Electric Power Applications, Vol. 146, No. 3, May 1999.

[10] H.-W. Kim and S.-K. Sul, "A New Motor Speed Estimator Using Kalman Filter in Low-Speed Range," IEEE Transactions on Industrial Electronics, Vol. 43, No. 4, August 1996, pp. 498-504.

[11] D. J. Atkinson, J. W. Finch and P. P. Acarnley, "Estimation of Rotor Resistance in Induction Motors," IEE Proceedings Electric Power Applications, Vol. 146, No. 3, January 1996.

[12] K. L. Shi, T. F. Chan, Y. K. Wong and S. L. Ho, "Speed Sensorless Control of an Induction Motor Drive Using an Optimized Extended Kalman Filter," IEEE Transactions on Industrial Electronics, Vol. 49, No. 1, February 2002, pp. 124-133.

[13] Y.-R. Kim, S.-K. Sul and M.-H. Park, "Speed Sensorless
Vector Control of Induction Motor Using Extended Kalman Filter," IEEE Transactions on Industrial Electronics, Vol. 30, No. 5, September/October 1994, pp. 1225-1233.

[14] S. Julier, J. K. Uhlmann and H. F. Durrant-Whyte, "A New Method for the Nonlinear Transformation of Means and Covariances in Filters and Estimators," IEEE Transactions on Automatic Control, Vol. 45, No. 3, March 2000, pp. 477-482.

[15] S. J. Julier and J. K. Uhlmann, "Unscented Filtering and Nonlinear Estimation," Proceedings of the IEEE, Vol. 92, No. 3, March 2004, pp. 401-422.

[16] K. Xiong, H. Y. Zhang and C. W. Chan, "Performance Evaluation of UKF-Based Nonlinear Filtering," Automatica, Vol. 42, 2006, pp. 261-270.

[17] B. Akin, U. Orguner and A. Ersak, "State Estimation Using Unscented Kalman Filter," Proceedings of IEEE, 2003, pp. 915-919.

[18] R. van der Merwe and E. A. Wan, "The Square-Root Unscented Kalman Filter for State and Parameter Estimation," Proceedings of the International Conference on Acoustics, Speech and Signal Processing, May 2001.

[19] J. Lie, Y. R. Zhong and H. P. Ren, "Speed Estimation of Induction Machines Using Square Root Unscented Kalman Filter," Proceedings of the IEEE, 2005, pp. 674-679.

[20] G. Evensen, "Ensemble Kalman Filter: Theoretical Formulation and Practical Implementation," Ocean Dynamics, Vol. 53, 2003, pp. 343-367.

[21] G. Burgers, P. J. Van Leeuwen and G. Evenson, “Analysis Scheme in Ensemble Kalman Filter," American Meteorological Society, Vol. 126, 1998, pp. 1719-1724.

[22] J. Prakash, S. C. Patwardhan and S. L. Shah, "Constrained State Estimation Using the Ensemble Kalman Filter," Proceedings of the American Control Conference, 2008, pp. 3542-3547.

[23] M. S. Arulampalam, S. Maskell, N. Gordon and T. Clapp, "A Tutorial on Particle Filters for Online Nonlinear/NonGaussian Bayesian Tracking," IEEE Transactions on Signal Processing, Vol. 50, No. 2, 2002, pp. 174-188.

[24] S. Gillijns, O. B. Mendoza, J. Chandrasekar, B. L. R. De Moor, D. S. Bernstein and A. Ridley, "What is the Ensemble Kalman Filter and How Well does it Work?" Proceedings of the American Control Conference, 2006, pp. 4448-4453.

[25] S. C. Patwardhan, J. Prakash and S. L. Shah, "Soft Sensing and State Estimation: Review and Recent Trends," Proceedings of IFAC Conference on Cost Effective Automation, Mexico, Vol. 1, Part 1, 2008. 


\section{Nomenclature}

\begin{tabular}{|c|c|}
\hline $\mathrm{P}_{\mathrm{p}}$ & No. of pole pairs \\
\hline $\mathrm{L}_{\sigma}=\sigma \mathrm{L}_{\mathrm{s}}$ & Stator transient inductance $(\mathrm{H})$ \\
\hline$\sigma$ & Leakage or Coupling factor \\
\hline $\mathrm{L}_{\mathrm{s}}$ & Stator inductance $(\mathrm{H})$ \\
\hline $\mathrm{R}_{\mathrm{s}}$ & Stator resistance $(\Omega)$ \\
\hline $\mathrm{L}_{\mathrm{r}}^{\prime}$ & $\begin{array}{l}\text { Rotor inductance referred to the stator } \\
\text { side }(\Omega)\end{array}$ \\
\hline $\mathrm{R}_{\mathrm{r}}^{\prime}$ & $\begin{array}{l}\text { Rotor resistance referred to the stator side } \\
(\Omega)\end{array}$ \\
\hline $\mathrm{V}_{\mathrm{s} \alpha}, \mathrm{V}_{\mathrm{s} \beta}$ & $\begin{array}{l}\text { Stator stationary axis components of } \\
\text { stator currents (V) }\end{array}$ \\
\hline$\psi_{\mathrm{r} \alpha}, \psi_{\mathrm{r} \beta}$ & $\begin{array}{l}\text { Rotor stationary axis components of } \\
\text { stator flux (V-s) }\end{array}$ \\
\hline $\mathrm{J}_{\mathrm{L}}$ & Total inertia of the IM $\left(\mathrm{Kg} \cdot \mathrm{m}^{2}\right)$ \\
\hline$\omega_{\mathrm{m}}$ & Angular velocity \\
\hline $\mathrm{x}$ & True state variables \\
\hline$\hat{\mathrm{x}}(\mathrm{k} \mid \mathrm{k})$ & Updated state estimates \\
\hline $\mathrm{y}(\mathrm{k})$ & Measured variables \\
\hline $\mathrm{u}(\mathrm{k})$ & Input variables \\
\hline $\mathrm{P}(\mathrm{k} \mid \mathrm{k})$ & Updated error covariance matrix \\
\hline $\mathrm{W}(\mathrm{k})$ & State noise vectors \\
\hline $\mathrm{F}$ & Jacobian matrix \\
\hline G & Non linear measurement function \\
\hline$\hat{\mathrm{x}}(\mathrm{k} \mid \mathrm{k}-1)$ & Predicted state estimates \\
\hline $\mathrm{P}(\mathrm{k} \mid \mathrm{k}-1)$ & Predicted error covariance matrix \\
\hline$\hat{\mathrm{y}}(\mathrm{k} \mid \mathrm{k}-1)$ & Predicted measurement \\
\hline$\Upsilon(\mathrm{k} \mid \mathrm{k}-1)$ & Innovation matrix \\
\hline $\mathrm{K}(\mathrm{k})$ & Kalman gain \\
\hline $\mathrm{V}(\mathrm{k})$ & Covariance matrix of innovation \\
\hline$\chi(\mathrm{k} \mid \mathrm{k}, \mathrm{i})$ & A set of $2 \mathrm{~L}+\mathrm{I}$ sigma points \\
\hline$\chi(\mathrm{k} \mid \mathrm{k}-1, \mathrm{i})$ & Predicted set of sigma points \\
\hline $\mathrm{P}_{\mathrm{ee}}(\mathrm{k})$ & Covariance matrix of innovations \\
\hline $\mathrm{P}_{\varepsilon \mathrm{e}}(\mathrm{k})$ & $\begin{array}{l}\text { Cross covariance matrix between the } \\
\text { predicted state estimate errors and } \\
\text { innovations }\end{array}$ \\
\hline W(i) & Associated weights \\
\hline
\end{tabular}

\section{Greek Symbols}

$\begin{array}{ll}\Phi & \text { State transition matrix } \\ \mu & \text { Mean of estimation error }\end{array}$

\section{Appendix-A}

\section{EKF Algorithm}

Owing to a wealth of literature exists on the EKF algo- rithm, here we merely present the filter equation in a succinct way. The basic idea of the EKF is to linearize $f$ and $g$ (Equations (3) and (4) listed in the Section 2) using a first order Taylor series expansion, and then apply the standard Kalman filter. We have assumed in this work that the initial state and the sequence $\{\mathrm{w}(\mathrm{k})\}$ and $\{\mathrm{v}(\mathrm{k})\}$ are white, Gaussian and independent of each other. The most acclaimed EKF is as follows:

The predicted state estimates are obtained as:

$$
\hat{\mathbf{x}}(\mathrm{k} \mid \mathrm{k}-1)=\hat{\mathbf{x}}(\mathrm{k}-1 \mid \mathrm{k}-1)+\int_{(\mathrm{k}-1) \mathrm{T}}^{(\mathrm{k}) \mathrm{T}} \mathrm{F}[\mathbf{x}(\tau), \mathbf{u}(\mathrm{k}-1)] \mathrm{d} \tau
$$

The covariance matrix of estimation errors in the predicted estimates is obtained as

$$
\mathrm{P}(\mathrm{k} \mid \mathrm{k}-1)=\Phi(\mathrm{k}) \mathrm{P}(\mathrm{k}-1 \mid \mathrm{k}-1) \Phi(\mathrm{k})^{\mathrm{T}}+\mathrm{Q}
$$

where

$$
\begin{aligned}
& \mathrm{A}(\mathrm{k})=\left[\frac{\partial \mathrm{F}}{\partial \mathrm{x}}\right]_{[\hat{x}(\mathrm{k}-1 \mid \mathrm{k}-1) \mathrm{u}(\mathrm{k}-1)]} ; \mathrm{C}(\mathrm{k})=\left[\frac{\partial \mathrm{G}}{\partial \mathrm{x}}\right]_{[\hat{x}(\mathrm{k}-1 \mid \mathrm{k}-1), \mathrm{u}(\mathrm{k}-1)]} \\
& \Phi(\mathrm{k})=\exp [\mathrm{A}(\mathrm{k}) * \mathrm{~T}]
\end{aligned}
$$

$\Phi(\mathrm{k})$ is nothing but Jacobian matrices of partial derivatives of $F[$.$] with respect to \mathrm{x}$ and $\mathrm{w}$ and $\mathrm{C}(\mathrm{k})$ is the Jacobian matrix of partial derivatives of $H[$.$] with$ respect to $\mathrm{x}$. The measurement prediction, computation of innovation and covariance matrix of innovation are as follows:

$$
\begin{gathered}
\hat{y}(\mathrm{k} \mid \mathrm{k}-1)=\mathrm{H}[\hat{\mathrm{x}}(\mathrm{k} \mid \mathrm{k}-1)] \\
\Upsilon(\mathrm{k} \mid \mathrm{k}-1)=\mathrm{y}(\mathrm{k})-\hat{\mathrm{y}}(\mathrm{k} \mid \mathrm{k}-1) \\
\mathrm{V}(\mathrm{k})=\mathrm{C}(\mathrm{k}) \mathrm{P}(\mathrm{k} \mid \mathrm{k}-1) \mathrm{C}(\mathrm{k})^{\mathrm{T}}+\mathrm{R}
\end{gathered}
$$

The Kalman gain is computed using the following equation

$$
\mathrm{K}(\mathrm{k})=\mathrm{P}(\mathrm{k} \mid \mathrm{k}-1) \mathrm{C}(\mathrm{k})^{\mathrm{T}} \mathrm{V}^{-1}(\mathrm{k})
$$

The updated state estimates are obtained using the following equation

$$
\hat{\mathrm{x}}(\mathrm{k} \mid \mathrm{k})=\hat{\mathrm{x}}(\mathrm{k} \mid \mathrm{k}-1)+\mathrm{K}(\mathrm{k}) \mathrm{r}(\mathrm{k} \mid \mathrm{k}-1)
$$

The covariance matrix of estimation errors in the updated state estimates is obtained as

$$
\mathrm{P}(\mathrm{k} \mid \mathrm{k})=[\mathrm{I}-\mathrm{K}(\mathrm{k}) \mathrm{C}(\mathrm{k})] \mathrm{P}(\mathrm{k} \mid \mathrm{k}-1)
$$

It should be noted that the calculation of the covariances and the gain of the EKF are the same as those of the linear Kalman filter. The EKF always approximates $\mathrm{p}\left[\mathrm{x}(\mathrm{k}) \mid \mathrm{Y}^{\mathrm{k}}\right]$ to be Gaussian. However, the distribu- 
tions of the various random variables are no longer normal after undergoing their respective nonlinear transformations. Moreover, EKF uses first order terms of the Taylor series expansion of the nonlinear functions, so, large errors will be introduced when the models are highly nonlinear.

\section{Appendix-B}

\section{Unscented Kalman Filter Algorithm (Julier and Uhlmann, 2000)}

The unscented transformation (UT) is a method for calculating the statistics of a random variable, which undergoes a nonlinear transformation. A set of $2 \mathrm{~L}+1$ sigma points $\chi(\mathrm{k} \mid \mathrm{k}, \mathrm{i})$ with the associated weights $\mathrm{W}(\mathrm{i})$ are chosen symmetrically about $\hat{\mathrm{x}}(\mathrm{k} \mid \mathrm{k})$ as follows:

$$
\begin{gathered}
\chi(\mathrm{k} \mid \mathrm{k}, 0)=\hat{\mathrm{x}}(\mathrm{k} \mid \mathrm{k}) \quad \mathrm{W}_{0}=\frac{\kappa}{\mathrm{L}+\kappa} \\
\chi(\mathrm{k} \mid \mathrm{k}, \mathrm{i})=\hat{\mathrm{x}}(\mathrm{k} / \mathrm{k})+(\sqrt{(\mathrm{L}+\kappa) \mathrm{P}(\mathrm{k} \mid \mathrm{k})})_{\mathrm{i}} \\
\mathrm{W}(\mathrm{i})=\frac{1}{2(\mathrm{~L}+\kappa)} \quad \mathrm{i}=1: \mathrm{L} \\
\chi(\mathrm{k} \mid \mathrm{k}, \mathrm{i})=\hat{\mathrm{x}}(\mathrm{k} \mid \mathrm{k})-(\sqrt{(\mathrm{L}+\kappa) \mathrm{P}(\mathrm{k} \mid \mathrm{k})})_{\mathrm{i}-\mathrm{L}} \\
\mathrm{W}(\mathrm{i})=\frac{1}{2(\mathrm{~L}+\kappa)} ; \mathrm{i}=\mathrm{L}+1 \ldots . .2 \mathrm{~L}
\end{gathered}
$$

where $\kappa$ is a tuning parameter and for Gaussian distribution the tuning parameter can be obtained from the following relation $\kappa=3-\mathrm{L}$. The $2 \mathrm{~L}+1$ sigma points have been derived from the state $(\hat{\mathrm{x}}(\mathrm{k} \mid \mathrm{k}))$ and covariance of the state vector $(\mathrm{P}(\mathrm{k} \mid \mathrm{k}))$, where $\mathrm{L}$ is the dimension of the state.

In the prediction step, the sigma points are propagated through the nonlinear differential equations to obtain the predicted set of sigma points as

$$
\begin{array}{r}
\chi(\mathrm{k} \mid \mathrm{k}-1, \mathrm{i})=\chi(\mathrm{k}-1 \mid \mathrm{k}-1, \mathrm{i})+\int_{(\mathrm{k}-1) \mathrm{T}}^{\mathrm{kT}} \mathrm{F}[\chi(\tau, \mathrm{i}), \mathbf{u}(\mathrm{k}-1)] \\
\mathrm{d} \tau ; \mathrm{i}=0: 2 \mathrm{~L}
\end{array}
$$

The predicted state estimates $(\hat{\mathrm{x}}(\mathrm{k} \mid \mathrm{k}-1))$ are obtained from the predicted sigma points as

$$
\hat{\mathrm{x}}(\mathrm{k} \mid \mathrm{k}-1)=\sum_{\mathrm{i}=0}^{2 \mathrm{~L}} \mathrm{~W}(\mathrm{i}) \chi(\mathrm{k} \mid \mathrm{k}-1, \mathrm{i})
$$

The error covariance matrix $(\mathrm{P}(\mathrm{k} \mid \mathrm{k}-1))$ is obtained from the predicted sigma points as

$$
\begin{aligned}
& \mathrm{P}(\mathrm{k} \mid \mathrm{k}-1)=\sum_{\mathrm{i}=0}^{2 \mathrm{~L}} \mathrm{~W}(\mathrm{i})[\chi(\mathrm{k} \mid \mathrm{k}-1, \mathrm{i})-\hat{\mathrm{x}}(\mathrm{k} / \mathrm{k}-1)] \\
& {[\chi(\mathrm{k} \mid \mathrm{k}-1, \mathrm{i})-\hat{\mathrm{x}}(\mathrm{k} / \mathrm{k}-1)]^{\mathrm{T}}+\mathrm{Q}}
\end{aligned}
$$

The predicted sigma points are propagated through the nonlinear measurement equation to obtain the predicted measurement as

$$
\hat{\mathrm{y}}(\mathrm{k} \mid \mathrm{k}-1)=\sum_{\mathrm{i}=0}^{2 \mathrm{~L}} \mathrm{~W}(\mathrm{i}) * \mathrm{H}[\chi(\mathrm{k} \mid \mathrm{k}-1, \mathrm{i})]
$$

The covariance matrix of the innovations $\left(\mathrm{P}_{\mathrm{ee}}(\mathrm{k})\right)$ and the cross covariance matrix between the predicted state estimate errors and innovations $\left(\mathrm{P}_{\varepsilon \mathrm{e}}(\mathrm{k})\right)$ are computed as:

$$
\begin{aligned}
& \mathrm{P}_{\mathrm{ee}}(\mathrm{k})=\sum_{\mathrm{i}=0}^{2 \mathrm{~L}} \mathrm{~W}(\mathrm{i})\{\mathrm{H}[\chi(\mathrm{k} \mid \mathrm{k}-1, \mathrm{i})] \\
& -\hat{\mathrm{y}}(\mathrm{k} \mid \mathrm{k}-1)\}^{*}\{\mathrm{H}[\chi(\mathrm{k} \mid \mathrm{k}-1, \mathrm{i})]-\hat{\mathrm{y}}(\mathrm{k} \mid \mathrm{k}-1)\}^{\mathrm{T}} \\
& \mathrm{P}_{\varepsilon \mathrm{e}}(\mathrm{k})=\sum_{\mathrm{i}=0}^{2 \mathrm{~L}} \mathrm{~W}(\mathrm{i})[\chi(\mathrm{k} \mid \mathrm{k}-1, \mathrm{i}) \\
& -\hat{\mathrm{x}}(\mathrm{k} / \mathrm{k}-1)]^{*}\{\mathrm{H}[\chi(\mathrm{k} \mid \mathrm{k}-1, \mathrm{i})]-\hat{\mathrm{y}}(\mathrm{k} \mid \mathrm{k}-1)\}^{\mathrm{T}} \\
& \Upsilon \Upsilon \mathrm{r} \mid \mathrm{k}-1)=\mathrm{y}(\mathrm{k})-\hat{\mathrm{y}}(\mathrm{k} \mid \mathrm{k}-1)
\end{aligned}
$$

The Kalman gain matrix $(\mathrm{K}(\mathrm{k}))$ can be determined as follows:

$$
\mathrm{K}(\mathrm{k})=\mathrm{P}_{\mathrm{\varepsilon e}}(\mathrm{k}) \mathrm{P}_{\mathrm{ee}}^{-1}(\mathrm{k})
$$

The updated state estimates $(\hat{\mathrm{X}}(\mathrm{k} \mid \mathrm{k}))$ are obtained using the linear update equation as in the Kalman filter.

$$
\hat{\mathrm{x}}(\mathrm{k} \mid \mathrm{k})=\hat{\mathrm{x}}(\mathrm{k} \mid \mathrm{k}-1)+\mathrm{K}(\mathrm{k}) \mid(\mathrm{k} \mid \mathrm{k}-1)
$$

The covariance matrix of error in the updated state estimates $(\mathrm{P}(\mathrm{k} \mid \mathrm{k}))$ are computed using

$$
\mathrm{P}(\mathrm{k} \mid \mathrm{k})=\mathrm{P}(\mathrm{k} \mid \mathrm{k}-1)-\mathrm{K}(\mathrm{k}) * \mathrm{P}_{\mathrm{ee}}(\mathrm{k}) \mathrm{K}^{\mathrm{T}}(\mathrm{k})
$$

The UKF does not approximate the nonlinear functions of system and measurement models as required by the EKF. Instead, the nonlinear functions are applied to sigma points to yield transformed samples, and the propagated mean and covariance are calculated from the transformed samples. 